\title{
A INFLUENNCIA DA RECREAÇÃO TERAPÊUTICA FRENTE A RECUPERAÇÃO DA CRIANÇA HOSPITALIZADA
}

\author{
Francisca Patricia Da Silva Lopes 1 \\ ORCID: 0000-0002-7478-7358 \\ Joseph Gabriel Cardoso Do Nascimento 2 \\ ORCID: 0000-0002-6276-9996 \\ Laurita Da Silva Cartaxo3 \\ ORCID: 0000-0002-7315-660X
}

\begin{abstract}
Resumo: A brincadeira no contexto hospitalar apresenta-se como ferramenta que auxilia no tratamento e promove restabelecimento da saúde da criança hospitalizada, portanto objetivase através deste estudo, analisar a acepção dos pais/responsáveis das crianças hospitalizadas acerca da recreação terapêutica em seu processo de recuperação. Trata-se de um estudo de abordagem qualitativa, de caráter exploratório-descritivo. Conduzido por uma coleta de dados da técnica do diário de pesquisa, das atividades extensionistas desenvolvidas pelos discentes do curso de graduação em Enfermagem do projeto: Brincadeira Hospitalar, promovendo Alegria e Terapia para Crianças e Adolescentes Hospitalizados, que foram realizadas em um hospital universitário no sertão paraibano. Os pais/responsáveis demonstraram acreditar no potencial terapêutico da recreação hospitalar como forma de promoção e recuperação da saúde, intervindo de forma efetiva e positiva na realidade local, reinventando o processo de hospitalização.
\end{abstract}

Palavras-chave: Criança hospitalizada. Estudantes de Enfermagem. Hospitalização. Jogos e Brinquedos. Pais.

1 Graduanda do curso de Bacharelado em Enfermagem pela Universidade Federal de Campina Grande -UFCG, campus Cajazeiras E-mail: patysilvasjp@hotmail.com

2 Graduando do curso de Bacharelado em Enfermagem pela Universidade Federal de Campina Grande -UFCG E-mail: josefgabriel26@gmail.com

3 Docente pela Universidade Federal de Campina Grande - UFCG. E-mail: lauritacartaxo@bol.com. br: 


\title{
THE INFLUENCE OF THERAPEUTIC RECREATION FACING THE RECOVERY OF THE HOSPITALIZED CHILD
}

\begin{abstract}
The play in the hospital context presents itself as a tool that assists in the treatment and promotes the restoration of the hospitalized child's health. Therefore, the objective of this study is to analyze the meaning of parents / guardians of hospitalized children about therapeutic recreation in their recovery process. This is a qualitative, exploratory-descriptive study. Conducted by a collection of data from the research journal technique, the extension activities developed by the undergraduate students in Nursing project: Hospital Play, promoting Joy and Therapy for Hospitalized Children and Adolescents, which were carried out in a university hospital in the hinterland paraibano. The parents / guardians demonstrated their belief in the therapeutic potential of hospital recreation as a way of promoting and recovering health, intervening effectively and positively in the local reality, reinventing the hospitalization process
\end{abstract}

Keywords: Child hospitalized. Nursing students. Hospitalization. Games and Toys. Parents.

\section{LA INFLUENCIA DE LA RECREACIÓN TERAPÉUTICA FRENTE LA RECUPERACIÓN DEL NIÑO HOSPITALIZADA}

Resumen: La broma en el contexto hospitalario se presenta como herramienta que auxilia en el tratamiento y promueve el restablecimiento de la salud del niño hospitalizado, por lo que se objetiva a través de este estudio, analizar la acepción de los padres / responsables de los niños hospitalizados acerca de la recreación terapéutica en su proceso de recuperación. Se trata de un estudio de abordaje cualitativo, de carácter exploratorio-descriptivo. Conducido por una recolección de datos de la técnica del diario de investigación, de las actividades extensionistas desarrolladas por los discentes del curso de graduación en Enfermería del proyecto: Brincadeira Hospitalar, promoviendo Alegría y Terapia para Niños y Adolescentes Hospitalizados, que se realizaron en un hospital universitario en el sertão Paraiba. Los padres / responsables demostraron creer en el potencial terapéutico de la recreación hospitalaria como forma de promoción y recuperación de la salud, interviniendo de forma efectiva y positiva en la realidad local, reinventando el proceso de hospitalización.

Palabras clave: Niño hospitalizado. Estudiantes de Enfermería. Hospitalización. Juegos y Juguetes. Los padres 


\section{INTRODUÇÃO}

A infância é uma fase do ciclo vital que está atrelada ao crescimento, desenvolvimento e descobertas, o que é facilitado através de brincadeiras que estimulam e permitem o conhecimento gradativo acerca de si, do próximo e do mundo. Um aspecto crucial para que isto aconteça é o ambiente em que essa criança se insere. Nesse sentido, Bortolote; Brêtas (2007) e Bulow et al. (2012) destacam que o episódio da perda da saúde e a hospitalização podem trazer implicações diversas ao seu desenvolvimento, pelo fato de restringir muitos dos estímulos ao qual a criança estaria exposta de estivesse em seu ambiente de convívio rotineiro.

Talvez o episódio da hospitalização seja a primeira crise que a criança experiencie, pela situação de vulnerabilidade biopsicossocial a qual está submetida pela condição clínica ou traumática. Nesta perspectiva, Hockenberry e Wilson (2011) destacam que pela deficiência de mecanismos de defesa, esses agentes estressores assumem na criança um poder potencial para trazer estresse, transtornos e sentimentos negativos que podem perdurar após a alta hospitalar.

Isso tudo é intensificado pela estrutura global e rígida das instituições hospitalares, que estão estruturadas para atender as necessidades de todos os indivíduos de maneira geral, com uma tendência de utilizar demasiadamente as tecnologias duras, como sofisticados instrumentos tecnológicos de trabalho, exames, entre outras coisas. Mehry (2002) reconhece que diante desse contexto cercado de tecnologias duras, as tecnologias leves, que favorecem a interação social e o protagonismo infantil, devem ser estimuladas, o que inclui a integralidade e humanização da assistência da equipe de saúde, a ludicidade e a brincadeira, implicando positivamente no desenvolvimento da criança hospitalizada.

Nessa perspectiva, alguns hospitais têm utilizado a recreação como auxílio no tratamento de crianças hospitalizadas, sendo chamada assim de recreação terapêutica ou recreação terapêutica hospitalar, como forma de promover o restabelecimento da saúde. A recreação hospitalar une diversão com terapia, utilizando-se de dinâmicas, que estão de acordo com a idade, limitação e necessidade de cada criança e seguindo o calendário de datas comemorativas para a criança e o adolescente, conforme também descreve Silva, Santos e Filipini (2011). 
Diante da necessidade de reafirmar e valorizar o papel e necessidades da criança hospitalizada, em 24 de março de 2005, o Congresso Nacional aprovou a Lei $\mathrm{n}^{\circ} 11.104$, que tornou realidade a Brinquedoteca Hospitalar, reconhecendo a brincadeira como necessidade da criança saudável ou comprometida e independente do ambiente em que se faça presente (BRASIL, 2005). Diante deste contexto, torna-se evidente a necessidade da utilização da brincadeira como instrumento para o bem estar biopsicossocial das crianças hospitalizadas, ganhando assim, um cunho terapêutico, seja ela realizada na brinquedoteca ou qualquer outro ambiente, por profissionais ou qualquer outra pessoa, desde que haja empatia, criatividade e proatividade.

Tendo em vista a importância da brincadeira no contexto hospitalar, objetiva-se através deste estudo, analisar a significação dada a recreação terapêutica frente a recuperação da criança hospitalizada segundo a ótica dos pais/responsáveis das crianças hospitalizadas em um hospital universitário no sertão paraibano.

\section{METODOLOGIA}

Trata-se de um estudo de abordagem qualitativa, de caráter exploratório-descritivo. Foi conduzido por uma coleta de dados orientada pela técnica do diário de pesquisa como uma tecnologia da prática investigativa, onde a vida se torna uma experiência em aberto e a pesquisa uma elaboração conjunta, satisfatória e significativa, lapidada lentamente a cada dia. Assim como Araújo et al.(2013) descreve, o diário de pesquisa se constitui como uma tecnologia na pesquisa qualitativa em saúde, que permite o registro das estratégias metodológicas e permite uma compreensão múltipla e ampla do objeto a ser estudado. Comportando-se como importante tecnologia de registro e memória dos acontecimentos da pesquisa do início ao fim, à proporção em que é desenvolvida.

Ao desenvolver atividades extensionistas, os graduandos discentes do curso de graduação em Enfermagem pela Universidade Federal de Campina Grande - UFCG no campus Cajazeiras, participantes como bolsistas e voluntários do projeto intitulado: Brincadeira Hospitalar, promovendo Alegria e Terapia para Crianças e Adolescentes Hospitalizados, cujas ações intervencionistas são realizadas nas instalações do HUJB, tiveram a oportunidade de experienciar momentos ímpares com crianças, profissionais e famílias 
que vivenciam o adoecimento junto a criança enferma. Assim, conforme sugerem Araújo et al.(2013) e Oliveira (2014), o diário de pesquisa em campo torna-se uma ferramenta para aproximar a teoria vista em sala em sala de aula a experiência prática, intensificando e atribuindo novos significados ao que conhece, efetivando a aprendizagem como significativa. Além disso, pode abrir a mente para novas possibilidades e modelos de cuidado em saúde, do olhar biopsicossocial, conhecendo um pouco melhor a história de vida de cada ator social, as experiências pelo adoecimento do membro familiar, operacionalizando-se pela entrevista informal. O diálogo informal quebra os parâmetros da pesquisa tradicional, ao passo que permite ao extensionista pesquisador, fazer observações comportamentais durante as falas, entender melhor os contextos sociais e ainda deixar suas impressões pessoais, tudo isso de maneira mutável e gradativa ao longo do tempo.

O diário utilizado pela pesquisa que embasa este estudo foi elaborado em caderno universitário e sendo remodelado naquilo que se mostrou necessário para facilitar sua utilização como memória da pesquisa. Sendo um único diário utilizado pelo grupo de discentes extensionistas, onde todos tem a oportunidade de registrar/ transcrever e refletir sobre o olhar dos pais/responsáveis das crianças hospitalizadas, dos profissionais de saúde da instituição e o seu próprio olhar acerca do evento da hospitalização e suas repercussões, que são vivenciados por todos, envolvendo diferentes experiências e perspectivas do processo de saúde, ao cuidado e adoecimento.

Foram sujeitos ativos da pesquisa acompanhantes (pais ou responsáveis) das crianças que estiveram internadas durante os meses de setembro a dezembro de 2018, em um hospital público universitário, o Hospital Universitário Júlio Maria Bandeira de Melo - HUJB, localizado na mesorregião do sertão paraibano, na cidade de Cajazeiras, com um porte médio de 58. 446 habitantes, e além disso, que se dispuseram a contribuir com o estudo.

Deste modo, cada membro do referido projeto de extensão produziu o diário de campo, de maneira coletiva e integrada, com o decorrer de cada ação interventiva, que acontecia durante todos os dias da semana, em horários alternados e com equipes formadas segundo disponibilidade de horários livre de aula de cada discente. Nesse diário de pesquisa as observações e experiências foram registradas, tendo um espaço determinado composto por quatro partes, sendo: A primeira parte destinada para identificação do tema da ação intervencionista realizada, nome dos extensionistas que a realizaram, data e 
horário. A segunda parte destinada ao registro das impressões e experiências de cada extensionista. A terceira destinada ao registro do diálogo e troca de saberes com os pais/responsáveis e a quarta para registro do diálogo e troca de saberes com os profissionais de saúde da instituição, onde para ambos a pergunta era a mesma: Como você avalia a importância da brincadeira hospitalar desenvolvida pela equipe do projeto, para a criança hospitalizada?

Para elaboração deste estudo, foram utilizadas as seguintes etapas:

$1^{\circ}$ Etapa: Elaboração do projeto de extensão, aprovação do mesmo pelo Comitê de Ética em pesquisa e pela Pró Reitoria de Pesquisa e Extensão da Universidade Federal de Campina Grande, no decorrer do mês de maio de 2018.

$2^{\circ}$ Etapa: Realização das ações interventivas junto à comunidade nas instalações do Hospital Universitário Júlio Maria Bandeira de Melo, dos meses de maio a dezembro de 2018.

$3^{\circ}$ Etapa: Produção coletiva do diário de campo das ações interventivas, dos meses de setembro a dezembro de 2018.

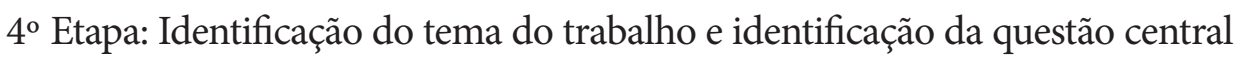
da pesquisa;

50 Etapa: Adoção dos critérios de inclusão, que foram os pais/responsáveis que demonstraram interesse em participar da pesquisa entre os meses de setembro a dezembro de 2018.

$6^{\circ}$ Etapa: Identificação de estudos na literatura nacional que colaborem com atemática abordada.

$7^{\circ}$ Etapa: Análise e interpretação dos dados por meio da análise de conteúdo, que, segundo Bardin (1977), permite descrever um conteúdo emitido em um processo de comunicação, seja através de falas ou textos. Além da delimitação da inter-relação entre os resultados obtidos das ações e os estudos encontrados na literatura, levantando assim, novas conclusões a partir do que foi evidenciado em cada estudo. Assim, foram divididos em 2 categorias, para facilitar a análise.

\section{RESULTADOS E DISGUSSÃO}

A recreação hospitalar pode ser realizada através de atividades artístico-lúdicas de cunho pedagógico (pintura, recorte, colagem, etc.) e terapêutico, através da utilização do brinquedo terapêutico. $\mathrm{O}$ brinquedo terapêutico tem a 
capacidade de diminuir a ansiedade gerada pela hospitalização como nenhum outro brinquedo comum. Assim, como Ribeiro et al. (2006) e Oliveira (2015) descrevem, o brinquedo terapêutico pode ser do tipo dramático (que permita encenação da sua experiência e emoções), capacitante de funções fisiológicas (brincadeiras que incentivam o autocuidado) ou preparatório (instrui a criança sobre as intervenções que serão feitas em seu corpo, facilitando a compreensão e esclarecendo dúvidas). Todos contribuindo para a continuidade do desenvolvimento infantil durante a hospitalização.

Neste sentido, através dos estudos de Ferreira et al (2014), Gesteira et al (2014) e Lima; Maia; Mitre (2015), é possível categorizar o desenvolvimento da criança hospitalizada em 4 grupos: Desenvolvimento físico-motor, intelectual, afetivo-emocional e social. No âmbito do desenvolvimento físico-motor, destaca-se o aprimoramento da coordenação motora e manipulação de objetos, que podem ser exploradas através de atividades de desenho, pintura, encaixe, modelagem, lançar ao alvo. No âmbito do desenvolvimento intelectual, destaca-se a ampliação da linguagem, desenvolvimento do raciocínio lógico, percepção, criatividade, concentração, através da comunicação, do teatro de fantoches, atividades pedagógicas, estímulo visual, auditivo e tátil direcionados, contação de histórias.

No tocante ao desenvolvimento afetivo-emocional, destacou-se o desenvolvimento de formas de lidar e reorganizar os sentimentos, diminuição de sentimentos negativos a hospitalização, maior vinculação aos pais e ganho de autonomia por parte das crianças, graças a experiência positiva adquirida através do fluir da imaginação em histórias de faz de conta, da utilização do brinquedo terapêutico, estímulo visual, auditivo e tátil direcionados. Já quanto ao desenvolvimento social, destacou-se a socialização, desenvolvimento de espírito de coletividade, através da partilha de brinquedos terapêuticos, diálogo, teatro, estímulo visual, auditivo e tátil direcionados.

Partindo desta perspectiva, os atores da pesquisa demonstraram, por unanimidade, acreditar no potencial terapêutico da recreação hospitalar. Seus discursos são pautados na ideia de que a brincadeira hospitalar gera aprendizagem (9\%), demonstração de afeto (18\%), distração e alegria (73\%). Deste modo a aprendizagem se relaciona com o desenvolvimento intelectual, a demonstração de afeto ao desenvolvimento afetivo emocional e também o social, enquanto a distração e alegria se relacionam ao desenvolvimento afetivo emocional. Conforme disposto abaixo: 


\section{ATORES QUE ASSOCIAM A BRINCADEIRA AO DESENVOLVI-} MENTO INTELECTUAL

"Eu desconhecia algumas dicas que eles passaram aqui como a forma certa de escovar os dentes. Minha filha escova sozinha e hoje ela pode aprender como é a escovação adequada. Mas ela sabe e até me ajuda lembrando a quantidade de pasta que devo usar" M.T.N., 40 anos.

2. ATORES QUE ASSOCIAM A BRINCADEIRA AO DESENVOLVIMENTO AFETIVO-EMOCIONAL

“Todas as manhãs em que eles vêm aqui, meu filho fica entretido e, com as brincadeiras, ele ri bastante. Nem parece que ele está em um hospital há 4 dias" C.S.L., 30 anos.

"Meu filho antes do projeto chega estava muito abatido, logo quando eles chegaram, pude notar a mudança no seu comportamento e ele diminuiu o choro. Esse projeto é muito importante dentro do hospital. " M.P. A, 34 anos.

"O projeto muda a rotina das crianças hospitalizadas, eles conseguem fazer com que elas sorriam, coisa que a bom tempo não era vista. ” J.M.S, 25 anos.

"Meu filho apresentou um quadro de melhora após as atividades realizadas por estes jovens, por tempo não estava vendo o sorriso no rosto do meu filho, e eles conseguiram arrancar. " M.C. O, 36 anos.

"Atividades como estas devem ser realizadas com rotina e com maior frequência aqui no hospital, pois é tão triste o processo em que nossas crianças passão aqui dentro, e o brincar faz com que eles se distraiam. " J.A.N, 28 anos.

“Todas essas ações desenvolvidas por este projeto são essenciais para minimizar o impacto da hospitalização ou da entrada da criança no ambiente hospitalar, até mesmo para um procedimento simples como uma consulta. O brincar, fazer leituras e encenações, despertam na criança sentimento de alegria, então isso é muito importante para o processo de recuperação. " M.P.N, 42 anos.

3. ATORES QUE ASSOCIAM A BRINCADEIRA AO DESENVOLVIMENTO AFETIVO-EMOCIONAL E SOCIAL

"Esse jovem vestido de Batman, conseguiu conquistar o carinho do meu filho e olhe que é difícil viu! Ontem quando vocês sairam ele ficou chorando, vejam só o quanto vocês fazem falta aqui. ” M.G.C.S., 35 anos.

"Atividades como estas quebram as rotinas estabelecidas pelo hospital, pois através da arte, do pintar, recortar nossas crianças sentem-se mais livres e não 
ficam tão tristes, acabam até fazendo amizade com os demais que estão aqui na enfermaria”. C.L.O., 25 anos.

Estes resultados representam que apesar de não poder obter resultados quantitativamente mensurável, as atividades recreativas desenvolvidas nas ações do projeto, a mudança na expressão de comportamento das crianças, o relato positivo dos pais, sugerem que foi possível estabelecer um bom vínculo com esses atores sociais, trocar saberes e criar um ambiente favorável para a humanização da assistência da equipe de saúde, melhorar a satisfação, alegria, sociabilização, restabelecer o bem estar e autoconfiança, além de dar continuidade ao desenvolvimento físico-motor, intelectual, afetivo-emocional e social das crianças, confirmando o que evidenciam os estudos de Ferreira et al (2014), Gesteira et al (2014) e Lima; Maia; Mitre (2015).

Deste modo, fica evidenciado que a recreação hospitalar é uma estratégia para interferir nos agentes estressores a criança e tornar a hospitalização mais amena e gerando efeitos múltiplos na dimensidão biopsicossocial de cada criança, sendo capaz de reduzir o tempo de reduzir medo, angústia e sofrimento, reduzir a permanência hospitalar e agilizar a alta, reduzindo custos e fazendo fluir melhor os serviços de saúde. O que vem a agregar aos estudos de Ribeiro et al. (2006) e Oliveira (2015), onde os pais destacaram influência direta na recuperação das crianças, seja pela compreensão do tratamento, distração, tranquilidade, valorização da saúde e até mesmo maior vinculação familiar. E também os estudos de Silva; Aguiar (2006) e Fioreti; Manzo; Regino (2016) que mostram a visão dos pais quanto a recreação hospitalar como uma oportunidade para a criança reorganizar a sua vida, seus sentimentos diminuir a ansiedade e entender seu processo saúde-doença.

\section{CONSIDERAÇÕES FINAIS}

Desta maneira, fica evidente que devido ao sofrimento físico, psíquico e a grande despersonalização que a criança sofre, em decorrência da hospitalização, há necessidade constante dela em expressar seus desejos, ansiedades e frustrações dentro da Pediatria, sendo a melhor maneira para isso através da brincadeira. Percebe-se que $\mathrm{O}$ brincar e a brincadeira podem tornar-se estratégias de ação terapêutica, onde a equipe de saúde, conhecendo as etapas do desenvolvimento infantil, pode planejar os jogos e as brincadeiras mais 
convenientes para estimular as múltipla inteligências e aprimoramentos para cada criança segundo sua subjetividade.

Para tanto, é possível reinventar o processo de hospitalização e foi o que foi ponto de destaque ao projeto Brincadeira Hospitalar, ao passo em que promove uma interface importante entre a universidade e os atores sociais, por intervir efetivamente na realidade local utilizando a alegria como um instrumento de promoção e recuperação da saúde, cumprindo o real papel que tem a extensão universitária. Além de fornecer um retorno para a sociedade de todos o investimento que é feito na comunidade acadêmica.

Através deste estudo, reitera-se ainda a importância da utilização do Brinquedo Terapêutico na prática assistencial à criança e sua família, bem como o maior investimento no uso de tecnologias leves na prática assistencial em saúde.

\section{REFERÊNCIAS}

ARAÚJO, L.F.S. et al. Diário de pesquisa e suas potencialidades na pesquisa qualitativa em saúde. Rev. Bras. Pesq. Saúde, Vitória, v.15, n. o 3, p. 53-61, jul-set 2013. Disponível em: http://periodicos.ufes.br/RBPS/article/view/6326. Acesso em: 20 abr. 2018.

BARDIN, L. Análise de conteúdo. Lisboa: Edições 70 Ltda, 1977.

BORTOLOTE, G.S.; BRÊTAS, J.R.S. O ambiente estimulador ao desenvolvimento da criança hospitalizada. Revista da Escola de Enfermagem da USP, São Paulo, v. 42, n. ${ }^{\circ}$ 3, p. 422-429, agosto 2007. Disponível em: http://www. scielo.br/scielo.php?script=sci_arttext\&pid=S0080-62342008000300002. Acesso em: 15 jul. 2018.

BRASIL. Lei $\mathrm{n}^{\circ} 11.104$, de 23 de março de 2005. Dispõe sobre a obrigatoriedade de instalação de brinquedotecas nas unidades de saúde que ofereçam atendimento pediátrico em regime de internação. Disponível em: https:// www.planalto.gov.br/ ccivil_03/_Ato2004-2006/2005/Lei/L11104.htm. Acesso em: 15 jul. 2018.

BÜLOW, D.M. et al. Avaliação do desenvolvimento infantil em enfermaria pediátrica de um hospital universitário. Contextos Clínicos, v. 5, n. ${ }^{\circ}$, p. 74-79, dezembro 2012. Disponível em: http://pepsic.bvsalud.org/scielo. php? script=sci_arttext\&pid=S1983-34822012000200002 . Acesso em: 15 jul. 2018. 
FALBO, B.C.P. et al. Estímulo ao desenvolvimento infantil: produção do conhecimento em Enfermagem. Revista Brasileira de Enfermagem, Brasília, v. 65 , n. ${ }^{\circ}$ 1, p. 148-154, fevereiro 2012. Disponível em: http://www.scielo.br/scielo.php?script=sci_arttext\&pid=S0034-71672012000100022. Acesso em: 15 jul. 2018.

FERREIRA, N.A.S. et al. Social representation of the hospital ludic: look of the child. Journal of Human Growth and Development, São Paulo, v.24, n. ${ }^{\circ}$ 2, p. 188 - 194, fevereiro 2014. Disponível em: http://pepsic.bvsalud.org/ scielo.php?script=sci_abstract\&pid=S0104-12822014000200011. Acesso em: 15 jul. 2018.

FIORETI, F.C.C.F.; MANZO, B.F.; REGINO, A.E.F. A ludoterapia e a criança hospitalizada na perspectiva dos pais. Revista Mineira de Enfermagem, Minas Gerais, v. 20, n. ${ }^{\circ}$ 1, p. 1- 6, setembro 2016. Disponível em:http://www. reme.org.br/artigo/detalhes/1110. Acesso em: 15 jul. 2018.

GESTEIRA, E.C.R. et al. Contos infantojuvenis: uma prática lúdica de humanização para crianças hospitalizadas. Revista Brasileira de Enfermagem da UFSM, Santa Maria, v.4, n. ${ }^{\circ 3}$, p. 575-588, setembro 2014. Disponível em: https://periodicos.ufsm.br/reufsm/article/view/12071. Acesso em: 15 jul. 2018.

HOCKENBERRY, M.J.; WILSON, D. WONG. Fundamentos de Enfermagem pediátrica. 8.ed. Rio de Janeiro: Guanabara Koogan, 2011.

LIMA, V.B.R.; MAIA, F.N.; MITRE, R.M.A. A percepção dos profissionais sobre o brinquedo em uma unidade intermediária de um hospital de média e alta complexidade. Cadernos Brasileiros de Terapia Ocupacional, São Paulo, v. 23, n. ${ }^{\text {4 }}$, p. 701-709, abril 2015. Disponível em http://www.cadernosdeterapiaocupacional.ufscar.br/index.php/cadernos/article/view/1110. Acesso em: 15 jul. 2018.

OLIVEIRA, C.S. et al. Brinquedo Terapêutico na assistência à criança: percepção de enfermeiros das unidades pediátricas de um hospital universitário. Rev. Soc. Bras. Enferm. Ped., São Paulo, v.15, n. ${ }^{\circ}$ 1, p 21-30, Jun., 2015. Disponível em: https://sobep.org.br/revista/images/stories/pdf-revista/vol15-n1/ vol_15_n_2-artigo-de-pesquisa-3.pdf. Acesso em: 20 de abr. 2018.

OLIVEIRA, R.C.M. (ENTRE)LINHAS DE UMA PESQUISA: o Diário de Campo como dispositivo de (in)formação na/da abordagem (Auto)biográfica.

Revista Brasileira de Educação de Jovens e Adultos, Salvador, v. 2, n. ${ }^{\circ} 4$, p. 
69-87, 2014. Disponível em: https://www.revistas.uneb.br/index.php/educajovenseadultos/article/view/1059. Acesso em: 20 abr. 2018.

RIBEIRO, C.A. et al. O brinquedo terapêutico na assistência à criança: o significado para os pais. Rev. Soc. Bras. Enferm. Ped. v.6, n. ${ }^{\circ}$ 2, p. 75-83 São Paulo, dez, 2006. Disponível em: https://sobep.org.br/revista/images/stories/ pdf-revista/vol6-n2/v.6_n.2-art2.pesq-o-brinquedo-terapeutico-na-assistencia-a-crianca.pdf. Acesso em: 20 abr. 2018.

SILVA P. F, SANTOS C.C.G, FILIPINI S. M. A Influência das Brincadeiras na Recuperação de Crianças Hospitalizadas: uma revisão de literatura. In: XV Encontro Latino Americano de Iniciação Científica e XI Encontro Latino Americano de Pós-Graduação da Universidade do Vale do Paraíba, 2011, São José dos Campos. Anais... São José dos Campos, 2011. v. 144, p. 71-75. Disponível em: http://www.inicepg.univap.br/cd/INIC_2011/anais/arquivos/0011_0586_01.pdf. Acesso em: 20 abr. 2018.

SILVA, E.A.; AGUIAR, O. X. A importância do brincar na pediatria em hospital geral. Revista Científica Eletônica de Psicologia, Garça, v.4, n. ${ }^{\circ}$, Nov., 2006. Disponível em: http://www.faef.revista.inf.br/imagens_arquivos/ arquivos_destaque/ZWouQUZvmOCJ84G_2013-5-10-15-32-53.pdf. Acesso em: 05 maio 2018.

SOUSA, L. C. et al. O brincar no contexto hospitalar na visão dos acompanhantes de crianças internadas. Rev. bras. crescimento desenvolv. hum. São Paulo, v. 25, n. 1, p. 41-49, 2015. Disponível em: http://pepsic.bvsalud.org/ scielo.php?script $=$ sci_arttext\&pid=S0104-12822015000100005\&lng=pt\&nr m=iso. Acesso em: 09 abr. 2018. 